\title{
AdMINISTRAÇÃO DA DÍVIDA PÚBLICA SOB UM REGIME DE METAS PARA INFLAÇÃO: EVIDÊNCIAS PARA O CASO BRASILEIRO*
}

\author{
Helder Ferreira de Mendonça ${ }^{\S}$ \\ Rubens Teixeira da Silva ${ }^{\mathrm{a}}$
}

\begin{abstract}
RESUMO
A utilização da taxa de juros como principal instrumento para a obtenção da meta de inflação e o fato de grande parte da dívida pública brasileira estar indexada a essa taxa faz com que haja uma reciprocidade entre a condução da política monetária e o gerenciamento da dívida pública. Foi observado que o uso da política monetária voltada para um processo de desinflação provocou um efeito negativo que não pode ser negligenciado para o equilíbrio fiscal. Os resultados indicam que a estratégia de aumentar a participação de títulos prefixados e indexados ao índice de preços mostra-se adequada para evitar uma deterioração na razão dívida/ PIB. Por outro lado, a ampliação do prazo médio da dívida pública ainda não trouxe os benefícios esperados. Uma variável que merece atenção é a credibilidade na condução da política monetária, uma vez que ela é capaz de contribuir tanto para uma redução na dívida pública quanto para o controle da inflação.
\end{abstract}

Palavras-chave: administração da dívida pública, metas para inflação, credibilidade.

\section{ABSTRACT}

The use of the interest rate as the main instrument in the search for inflation target and the fact that large part of the Brazilian public debt is indexed to this rate implies a reciprocity between the conduction of monetary policy and public debt management. It was observed that the use of the monetary policy focused on a disinflationary process implied a negative effect that cannot be neglect for the fiscal equilibrium. The findings denote that the strategy of increasing the share of prefixed public bonds and indexed to the price index is adequate to avoid deterioration in the public debt/GDP ratio. On the other hand, an increase in the average maturity of public debt still not provoked the expected advantages. A variable that deserves attention is the credibility in the conduction of the monetary policy because it is capable to promote a fall in the public debt and improves the control on inflation.

Keywords: public debt management, inflation targeting, credibility.

JEL classification: E52, E62, E63.

\footnotetext{
* Agradecemos aos profícuos comentários realizados por um parecerista anônimo desta revista. Possíveis erros e omissões são de exclusiva responsabilidade dos autores. As idéias expressas neste artigo são de responsabilidade dos autores, não refletindo necessariamente a opinião do Banco Central do Brasil.

$\S \quad$ Universidade Federal Fluminense - Departamento de Economia e Conselho Nacional de Desenvolvimento Científico e Tecnológico (CNPq). E-mail: helderfm@hotmail.com.

a Banco Central do Brasil. E-mail: rubensteixeira1000@yahoo.com.br.

Recebido em agosto de 2007. Aceito para publicação em agosto de 2008.
} 


\section{INTRODUÇÃO}

O Plano Real foi marcado pelo sucesso no controle da inflação. A principal estratégia adotada no momento de sua implementação foi a adoção de uma âncora cambial (crawling peg) para o controle de preços. Entretanto, em função de a taxa de câmbio ter se tornado sobrevalorizada houve uma deterioração no saldo de transações correntes. Destarte, a economia tornou-se dependente de capitais externos, notadamente de curto prazo, como forma de manter as reservas internacionais em níveis elevados para proteger a estabilidade da taxa de câmbio. As instabilidades externas geradas pelas crises asiática (outubro de 1997) e russa (setembro de 1998) levaram à mudança do regime cambial e provocaram uma forte elevação na taxa de juros. Devido ao fato de grande parte da dívida pública ser indexada pela taxa over-Selic e pela taxa de câmbio, houve uma pressão sobre o endividamento público que culminou com uma forte elevação na razão dívida/PIB.

Com a substituição do regime de câmbio, tornou-se necessária a busca de uma nova âncora nominal para guiar as expectativas de inflação. Assim, em junho de 1999, foi adotado o regime de metas para inflação. A principal motivação para a introdução desse regime monetário se deve à expectativa de que o uso desta estratégia eliminaria a incerteza causada pela desvalorização da moeda e seria capaz de estabilizar a inflação.

Uma importante função do uso da estratégia supracitada é o papel de guia para a formação de expectativas da inflação futura dos agentes econômicos. Todavia, o sucesso do regime de metas para inflação depende da credibilidade do Banco Central. Dado que a reputação é uma condição básica para desenvolver credibilidade, é necessário que o público acredite que o anúncio da meta anunciada será alcançada com sucesso. ${ }^{1}$ Em outras palavras, a idéia implícita nesse regime monetário é que o anúncio da meta de inflação, aliado a um compromisso firme do Banco Central em alcançá-la, aumenta o grau de confiança dos agentes econômicos na condução da política monetária, o que, por conseguinte, permite um maior controle sobre a inflação. ${ }^{2}$

É importante ressaltar que, sob o regime de metas para inflação, a falta de credibilidade da autoridade monetária (expectativa de que a meta de inflação não será cumprida) gera uma pressão para o aumento da taxa de juros. A justificativa é que a taxa de juros é o principal instrumento à disposição do Banco Central para fazer a convergência entre a expectativa da taxa de inflação futura e a meta anunciada. Portanto, considerando-se uma estrutura da dívida pública em que a taxa de juros básica é o principal indexador (tal como no caso brasileiro), as implicações sobre o lado fiscal são diretas. ${ }^{3}$

1 A importância da credibilidade e reputação para a condução da política monetária é apresentada originalmente por Barro e Gordon (1983). Para uma análise dos desdobramentos do debate regras versus discrição, ver Mendonça (2002).

2 Para uma análise envolvendo credibilidade do Banco Central e o regime de metas para inflação aplicada ao caso brasileiro, ver Mendonça (2007).

3 Entre janeiro de 2000 e agosto de 2006 a média da dívida pública brasileira indexada à taxa Selic corresponde a $55,29 \%$. 
De acordo com Sargent e Wallace (1981) uma dívida pública elevada contribui para uma rigidez na redução da taxa de juros. Ademais, conforme destacado por Giavazzi e Pagano (1990) há uma conexão entre a maturidade da dívida pública e a determinação da taxa de juros. A idéia é que uma maturidade da dívida pública curta (longa) pode estar associada a uma alta (baixa) taxa de juros devido ao alto (baixo) risco de default. Ainda sob a mesma visão, a concentração de vencimentos não é adequada devido ao alto custo no caso de uma crise de confiança.

Com o objetivo de evitar que a dívida pública entrasse em uma rota explosiva e de aumentar a credibilidade na condução da política econômica voltada para a estabilidade de preços, em novembro de 1999, o Tesouro Nacional anunciou uma estratégia de alongamento do prazo da dívida pública federal. Além disso, foram anunciados esforços para melhorar a composição da dívida pública. O objetivo principal era aumentar a parcela de títulos prefixados e indexados ao índice de preços, e reduzir o porcentual da dívida indexada à taxa over-Selic e à taxa de câmbio.

Embora a literatura padrão sobre a administração da dívida pública sugira que um aumento no prazo médio represente uma estratégia adequada para evitar um risco de default, há custos que não podem ser desprezados. Por exemplo, quando uma economia não possui credibilidade suficiente, o resultado desse procedimento é a vigência de uma elevada taxa de juros (KING, 1995). Dado que o Brasil representa o caso de uma economia em que a credibilidade ainda se encontra em uma fase de desenvolvimento, torna-se relevante verificar se a estratégia adotada para a administração da dívida pública (mudança do perfil de indexação e o alongamento do prazo de maturidade) influenciou a taxa over-Selic.

Além desta introdução, o artigo é constituído de mais quatro seções. Na seção 2, é feita uma breve apresentação da literatura sobre administração da dívida pública. Na seção 3, são destacados os principais pontos que caracterizam o comportamento da dívida pública no período recente. A seção 4 apresenta uma análise empírica baseada em estimações de mínimos quadrados ordinários (MQO) e de um modelo auto-regressivo vetorial (VAR) para avaliar a estratégia de gerenciamento da dívida pública adotada pelo governo brasileiro. Por último, é apresentada a conclusão do artigo.

\section{MODELOS DE GERENCIAMENTO DA DÍVIDA PÚBLICA}

O gerenciamento da dívida pública está diretamente relacionado à aquisição de credibilidade da política econômica. Se um país não é capaz de sinalizar aos agentes econômicos que a sua dívida será honrada, nenhum outro fundamento da economia será capaz de evitar o default. Como a aquisição dos títulos públicos que financiam a dívida pública mobiliária é feita pelo setor privado, não é desprezível a influência desses credores na construção da credibilidade. Assim, as expectativas do mercado interferem na demanda desses títulos e, portanto, na capacidade de o governo rolar a sua dívida. 
A interação entre os agentes privados e o governo interfere na escolha da estratégia de administração da dívida pública. Esta influência está relacionada ao prazo ótimo, ao nível de indexação da dívida e na definição dos indexadores a serem utilizados. Portanto, é recomendável a utilização de estratégias que sejam capazes de neutralizar os impactos provocados por choques externos ou internos que coloquem em risco a solvência fiscal. Em suma, uma administração ideal para a dívida pública seria aquela capaz de eliminar os problemas relacionados à inconsistência temporal.

No período recente, diversos teóricos têm se dedicado à análise da administração da dívida pública. O principal desafio é obter uma estratégia capaz de garantir a estabilidade financeira e minimizar os efeitos gerados por crises de confiança. Com esse objetivo, Giavazzi e Pagano (1990), Calvo e Guidotti (1990), Missale, Giavazzi e Benigno (2002), Barro (2003) e Giavazzi e Missale (2004) desenvolveram modelos de gerenciamento da dívida pública que buscam encontrar medidas que contribuam para a estabilização da razão dívida/PIB. ${ }^{4}$

Giavazzi e Pagano (1990) tomam como ponto fundamental o problema da rolagem da dívida pública. Nesse aspecto, tornam-se relevantes o tamanho da dívida, o prazo e a estrutura de vencimento. Sob esta perspectiva, é avaliado se o risco de ocorrência de uma crise de confiança pode ser atenuado por meio da escolha de determinada estrutura de maturidade da dívida pública. A crise de confiança é interpretada como a probabilidade de mudanças no regime da política econômica. A análise é feita considerando-se um regime de câmbio fixo e a dívida encontra-se concentrada em poucos vencimentos. Como conseqüência, em períodos de crise, o governo é obrigado a pagar um prêmio de risco mais elevado (aumento da taxa de juros) o que, por conseguinte, aumenta a probabilidade de default. A solução encontrada por esses autores para minimizar o problema é o alongamento dos prazos médios e a distribuição dos vencimentos ao longo do tempo.

Calvo e Guidotti (1990) avaliam o impacto e o grau de otimização de diferentes coeficientes de indexação e estruturas de vencimento da dívida pública, tomando como restrição uma função de perda social em função da carga tributária e do nível de inflação. Ademais, é analisada a estrutura da dívida ao longo de dois períodos, partindo da hipótese de que o governo do primeiro período compromete completamente as ações do governo seguinte. O resultado obtido revela que a indexação é desejável como forma de evitar o uso do imposto inflacionário para a redução do valor real do estoque da dívida e que a indexação total da dívida implica um uso mais intenso da carga tributária como fonte de financiamento. A conclusão é que a estratégia ótima de gerenciamento da dívida deve ser baseada no alongamento dos prazos de vencimento e na indexação parcial do estoque da dívida.

Missale, Giavazzi e Benigno (2002) fazem uma análise empírica levando em conta a determinação da maturidade dos títulos da dívida pública adequado a uma estabilização fiscal. No caso de informação assimétrica, isto é, quando os investidores não percebem a exeqüibilidade

4 Para uma análise formal dos dois primeiros modelos mencionados, ver Mendonça (2004b). Quanto à questão de qual dos modelos citados é mais adequado para o caso brasileiro, ver Mendonça e Vivian (2008). 
das medidas anunciadas, o governo pode emitir títulos da dívida de curto prazo. Esse comportamento pode ser interpretado como um recurso do governo para se prevenir do custo elevado da dívida de longo prazo devido às expectativas de alta da taxa de juro futura. Os autores concluem que uma estrutura de dívida mais longa é capaz de reduzir o risco de refinanciamento. Portanto, a probabilidade de sucesso do esforço fiscal é maior, independente do custo esperado do serviço da dívida.

Barro (2003) verificou que a suavização da carga tributária estimula o governo a emitir títulos da dívida pública, cujos pagamentos são contingentes às realizações dos seus gastos e à base tributária. De acordo com esta perspectiva, no caso dos valores dos gastos serem iguais em todos os períodos, a dívida pública deve ser estruturada por perpetuidades indexadas (consols). O argumento é que essa estrutura é capaz de isolar a restrição orçamentária de variações inesperadas de títulos indexados ao índice de preços de diferentes maturidades.

O modelo desenvolvido por Giavazzi e Missale (2004) admite que o principal objetivo do gerenciamento da dívida pública no Brasil é a estabilização da razão dívida/PIB. Para alcançar este objetivo, o governo deve encontrar fontes de financiamento que ofereçam baixos custos e baixa variabilidade de seus retornos. Sob essa perspectiva, a escolha dos instrumentos de dívida pública implica um trade-off entre o risco e o custo esperado do serviço da dívida. A recomendação de política é que a maior parte da dívida pública brasileira deveria ser constituída por títulos prefixados (não indexados). Ademais, a parcela indexada deveria ter o índice de preços como principal indexador e as emissões de títulos indexados à taxa over-Selic e à taxa de câmbio deveriam ser reduzidas.

Com base nos modelos supracitados, observa-se que as principais recomendações para o gerenciamento da dívida pública podem ser sumariados em quatro pontos básicos: (i) necessidade de alongamento do prazo da dívida; (ii) aumento da parcela da dívida prefixada; (iii) diminuição da participação dos títulos indexados à taxa Selic e à taxa de câmbio, e (iv) indexação de grande parte da dívida ao índice de preços.

\section{EVOLUÇão dA DÍVIDA PÚBLICA BRASILEIRA NO PERÍODO RECENTE}

O objetivo desta seção é traçar a evolução da dívida pública brasileira no período compreendido entre janeiro de 2000 a agosto de 2006. De janeiro de 2000 a agosto de 2006, a razão dívida/PIB tem-se mantido, em média, acima de 50\% (vide Figura 1). Observa-se que houve um pico na razão dívida/PIB em setembro de 2002, mês que antecedeu a penúltima eleição presidencial. Neste período pré-eleitoral, devido às incertezas geradas pela expectativa de o Brasil eleger um presidente de oposição em substituição àquele que havia implementado a política econômica vigente, houve perturbações que levaram a um overshooting da taxa de câmbio, que resultou na alta da razão dívida/PIB. 
De acordo com Favero e Giavazzi (2003), o Banco Central perde a capacidade de conduzir a política monetária em período de alta volatilidade da dívida pública (fundamentos fiscais não sólidos). Ademais, os autores estimam que, quando a razão dívida/PIB ultrapassa o porcentual de 55\%, o Banco Central torna-se incapaz de implementar uma política econômica que garanta a estabilidade de preços. Como pode ser observado na Figura 1, este porcentual foi ultrapassado algumas vezes, especialmente no segundo semestre de 2002.

\section{Figura 1 - Evolução da razão dívida/PIB}

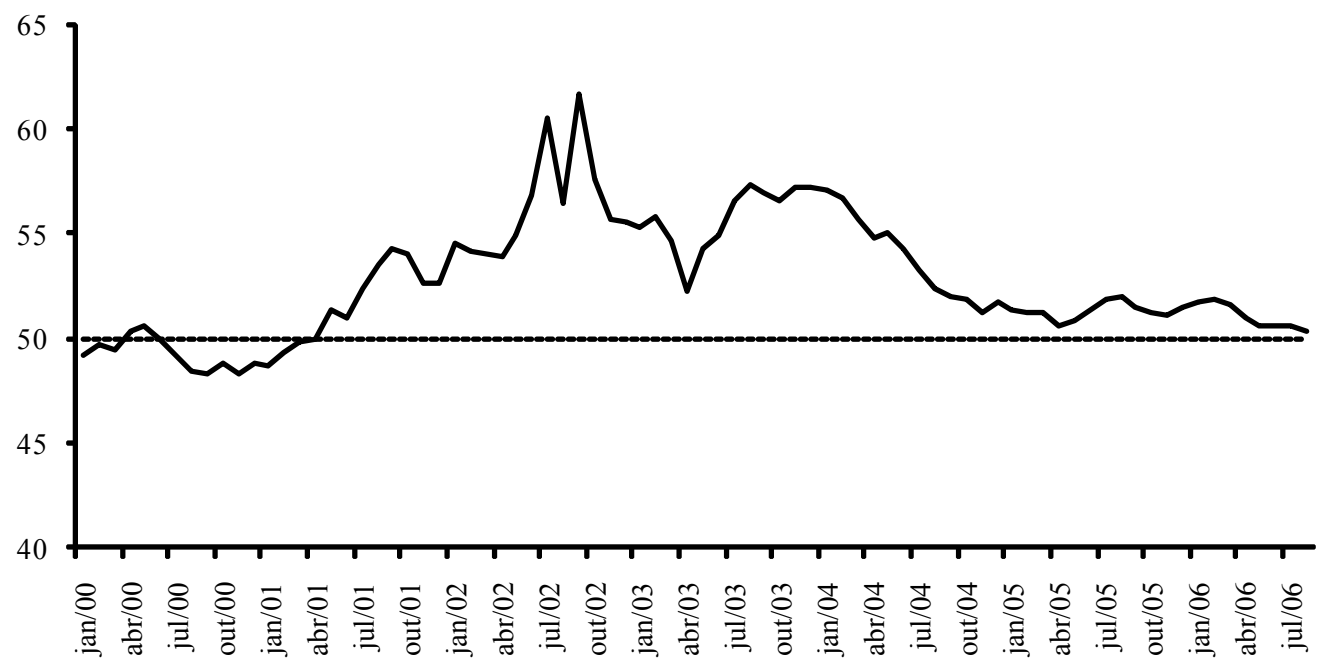

Fonte: Banco Central do Brasil.

Em momentos conhecidos como stress do mercado, a diminuição da demanda por títulos prefixados faz com que as instituições detentoras desses títulos entrem em movimento de stop loss, que se traduz em limitação de perdas. Com isso, há um efeito imediato sobre as taxas do mercado futuro. Nesses momentos, o Banco Central do Brasil e o Tesouro Nacional são impelidos a recomprar os títulos sob a justificativa de manter a sua liquidez e garantir a rolagem da dívida pública, assumindo, com isso, os riscos das instituições em posições compradas desses títulos.

A volatilidade verificada no mercado financeiro doméstico ao longo de 2001 e os riscos que o mercado via na eleição de um novo presidente no final de 2002 levaram à queda da demanda por títulos prefixados (próximo a $2 \%$ ) e ao aumento na demanda por títulos indexados à Selic (mais de 60\%). A justificativa para esse comportamento se deve ao fato de que a demanda por títulos pós-fixados torna-os preferíveis aos prefixados em cenário de risco. Observa-se que o período de maior alta na razão dívida/PIB (segundo semestre de 2002) coincidiu com o período em que uma parcela significativa da dívida pública estava indexada à taxa de câmbio e houve uma forte desvalorização da moeda (vide Figura 2). 
Figura 2 - Dívida pública indexada à taxa de câmbio e taxa de câmbio

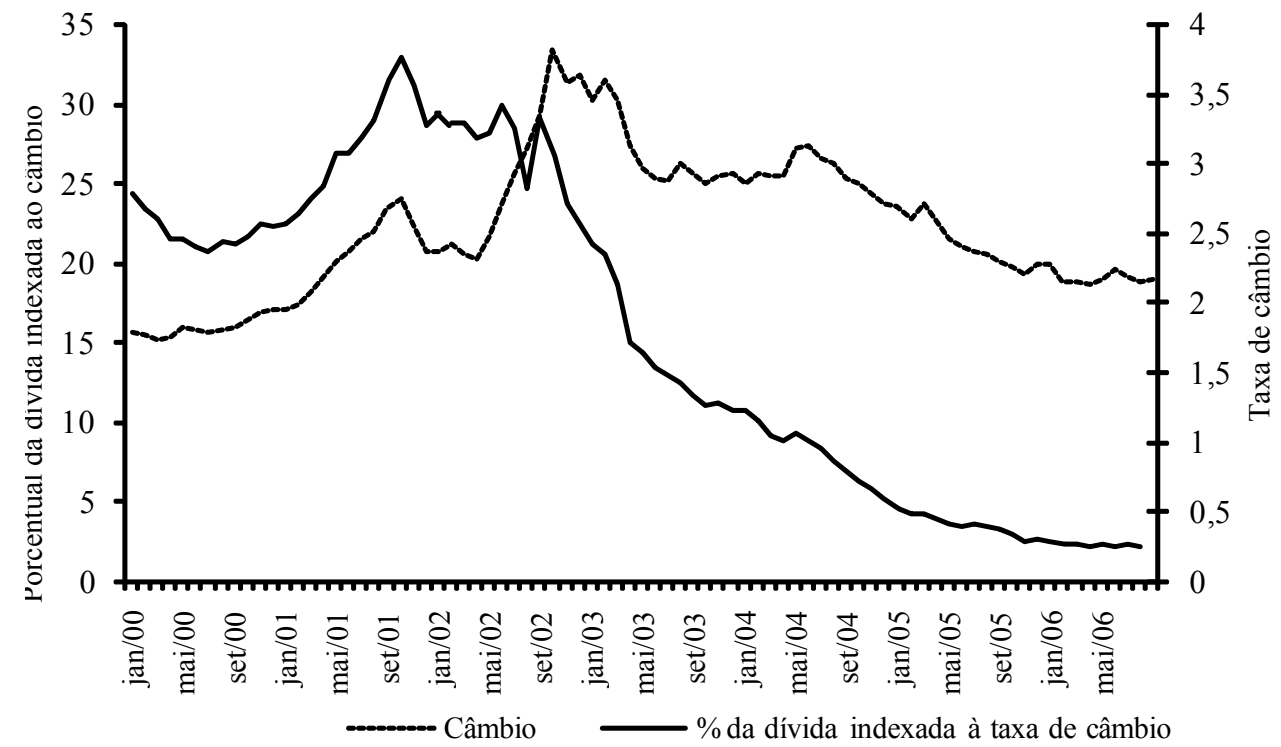

Fonte: Banco Central do Brasil e Tesouro Nacional.

De forma análoga ao caso anterior, a retomada na elevação da razão dívida/PIB, depois de um breve arrefecimento no primeiro trimestre de 2003, está associada a um período em que houve um aumento significativo na taxa de juros e na parcela da dívida pública indexada à taxa Selic (vide Figura 3).

Figura 3 - Porcentual da dívida indexada à taxa Selic versus taxa Selic

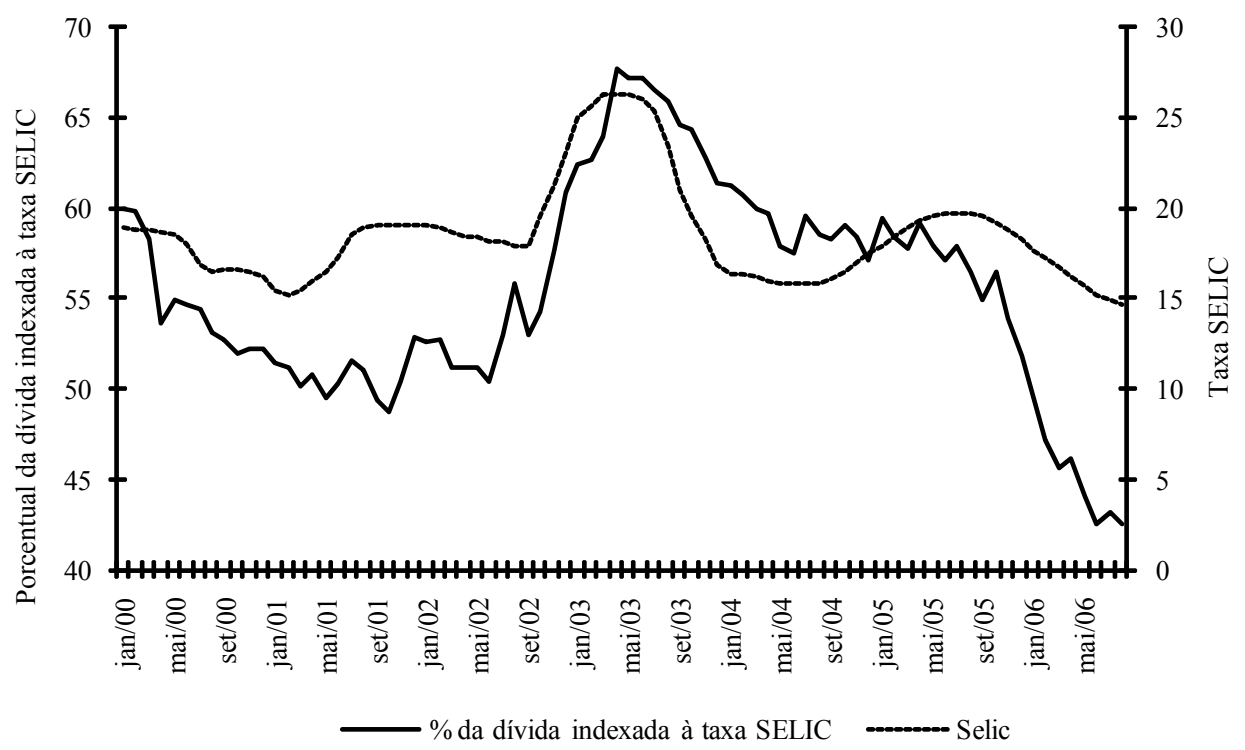

Fonte: Banco Central do Brasil e Tesouro Nacional. 
Conjugaram-se, portanto, em ambos os períodos, o aumento da parcela da dívida pública indexada à taxa de câmbio (quando a taxa de câmbio era mais elevada) e o aumento da parcela indexada à taxa Selic (quando a taxa Selic era mais elevada). Portanto, a pressão sobre a dívida tornou-se mais acentuada. Esta pressão começou a ser atenuada a partir do segundo semestre de 2003 quando os agentes econômicos perceberam que o novo Presidente da República não faria alterações substanciais na condução da política econômica. Como conseqüencia, houve uma queda continuada da taxa de câmbio e da taxa de juros básica da economia, que contribuiu para o decréscimo da razão dívida/PIB a partir de 2004.

A mudança no cenário macroeconômico tem contribuído para um novo perfil da dívida pública brasileira no período recente. Com base nas informações divulgadas pelo Banco Central do Brasil (Relatório de inflação), pode-se perceber que a parcela de títulos prefixados vem aumentando ao longo do tempo (31,49\% em agosto de 2006) ao passo que os títulos indexados à taxa Selic vem diminuindo (42,50\% em agosto de 2006). Destarte, em agosto de 2006, a razão dívida/PIB alcançou 50,28\%, depois de ultrapassar 60\% em julho e setembro de 2002.

Na busca de uma melhor administração da dívida pública, o Tesouro Nacional aumentou gradualmente a participação de títulos indexados ao índice de preços (alcançando 31,49\% em agosto de 2006). Outra medida relevante foi a redução do porcentual de títulos indexados à taxa de câmbio a partir do final de 2002, alcançando 2,24\% em agosto de 2006. Além disso, foi observada uma redução significativa na participação dos títulos públicos indexados à taxa Selic (42,5\% em agosto de 2006, bem menor que os 67,68\% registrados em abril de 2003 - vide Figura 4).

É importante notar que o prazo médio da dívida pública sofreu significativa elevação entre 2000 e 2001 (máximo de 36,23 meses em agosto de 2001). Todavia, desde junho de 2002, é observada uma redução no prazo médio (29,84 meses em agosto de 2006). Uma justificativa para esse comportamento se deve à incerteza provocada pelo favoritismo do candidato que fazia oposição à condução da política macroeconômica na penúltima eleição presidencial. Conforme pode ser observado pela Figura 5, além do aumento no prazo médio não ter se sustentado, a volatilidade foi significativa ao longo do período. 


\section{Figura 4 - Evolução da composição da dívida pública por indexador}

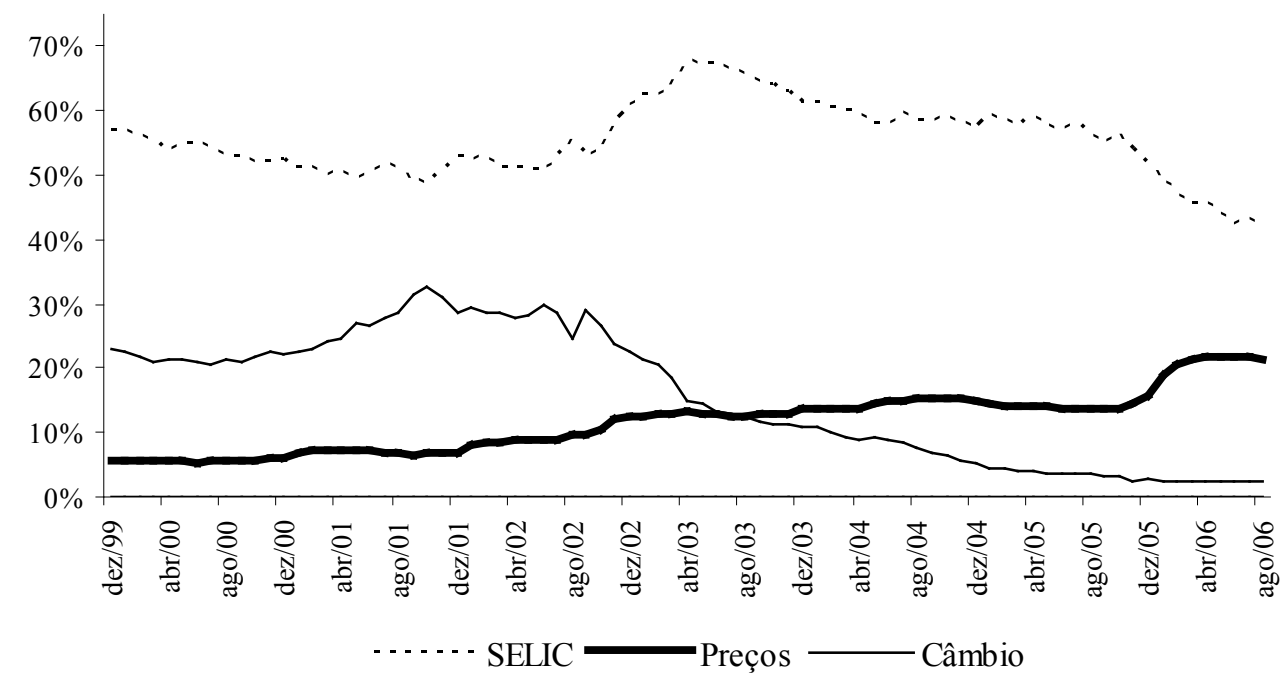

Fonte: Tesouro Nacional.

Não se deve desprezar as conseqüências da dinâmica da dívida pública para o regime de metas de inflação e, por conseguinte, para a estabilidade da economia. Em última instância, a autoridade monetária não pode determinar a taxa de juros sem avaliar os efeitos sobre a razão dívida/PIB. Esta perspectiva é reforçada pelo fato de a credibilidade na política econômica ainda não estar consolidada. Logo, o temor da ocorrência de um default da dívida pública pode levar a uma reversão das expectativas do setor privado contribuindo para a instabilidade dos fundamentos econômicos. 
Figura 5 - Evolução do prazo médio da dívida pública

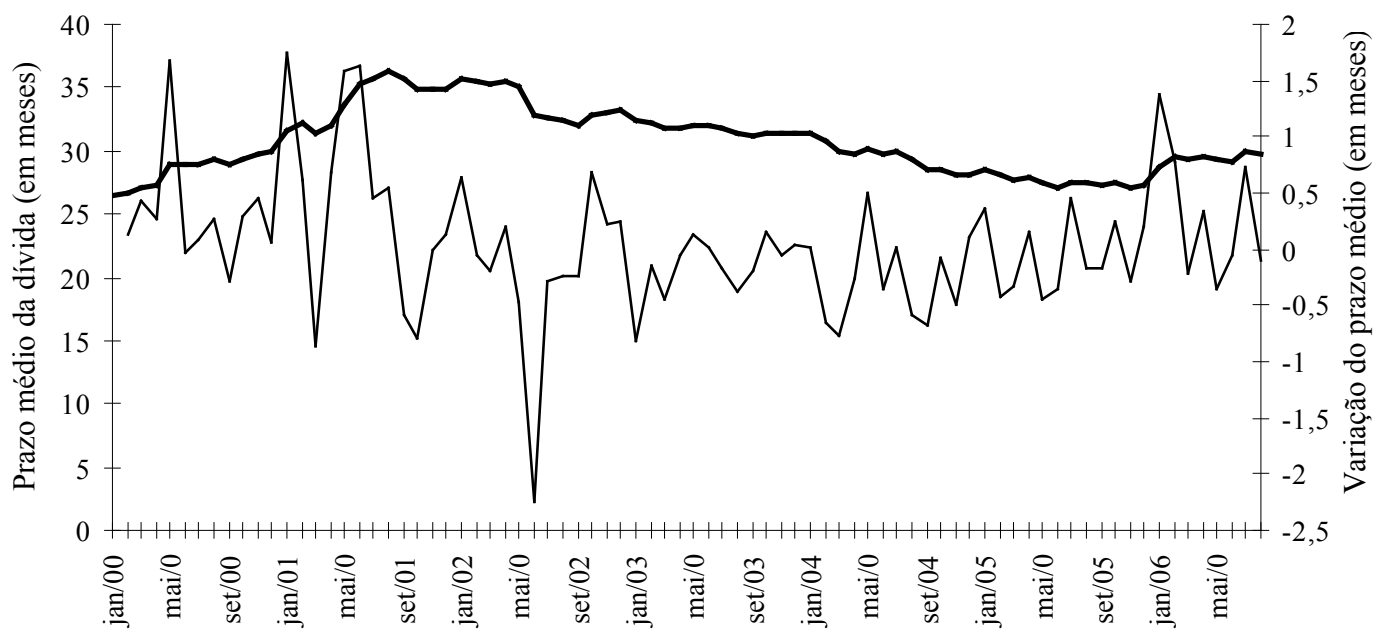

— Prazo médio da dívida pública —— Variação do prazo médio da dívida pública

Fonte: Tesouro Nacional.

\section{ANÁLISE EMPÍRICA}

Levando em consideração os modelos teóricos de gerenciamento da dívida pública mencionados na segunda seção, é feita uma análise empírica do caso brasileiro para o período entre janeiro de 2000 e agosto de 2006 por meio da aplicação de mínimos quadrados ordinários (MQO) e de um modelo auto-regressivo vetorial (VAR). As variáveis utilizadas na análise são: ${ }^{5}$ razão dívida/PIB (DIVPIB), parcela da dívida composta por títulos prefixados (PREFIX), parcela da dívida composta por títulos indexados à Selic (p_SELIC), parcela da dívida composta por títulos indexados à taxa de câmbio (p_CAMBIO), parcela da dívida composta por títulos indexados ao índice de preços (p_IP), credibilidade (CREDIB), prazo médio da dívida pública federal interna (PMDFI), taxa de juros básica da economia (SELIC), inflação medida pelo IPCA (INF), ${ }^{6}$ necessidade de financiamento do setor público primário (NFSPP). A estatística descritiva das variáveis é apresentada na Tabela 1.

5 Todas as variáveis utilizadas possuem freqüência mensal e as fontes de dados foram o Banco Central do Brasil e o Instituto de Pesquisa Econômica Aplicada.

6 O Índice Nacional de Preços ao Consumidor Amplo (IPCA) reflete a variação dos preços das cestas de consumo das famílias com renda mensal, independente da fonte, de 1 a 40 salários mínimos e é o índice oficial para a mensuração da inflação no caso brasileiro. 


\section{Tabela 1 - Estatística descritiva}

\begin{tabular}{lccccc}
\hline & Média & Mediana & Máximo & Mínimo & Desvio padrão \\
\hline DIVPIB & 52,8090 & 51,9050 & 61,6500 & 48,2900 & 2,9237 \\
PREFIX & 14,4651 & 13,6312 & 31,4945 & 1,91116 & 7,7997 \\
P_SELIC & 55,3079 & 54,8660 & 67,6846 & 42,4971 & 5,8686 \\
P_CAMBIO & 15,5942 & 14,7611 & 32,8524 & 2,2328 & 10,0186 \\
P_IP & 11,7136 & 12,7503 & 21,9430 & 5,4331 & 4,6592 \\
CREDIB & 0,4196 & 0,4025 & 0,9850 & 0,0000 & 0,3544 \\
PMDFI & 30,7143 & 29,9504 & 36,2300 & 26,4500 & 2,6655 \\
SELIC & 18,5404 & 18,2750 & 26,3200 & 14,6600 & 2,8578 \\
INF & 0,6096 & 0,5200 & 3,0200 & $-0,2100$ & 0,5158 \\
NFSPP & $-4,1318$ & $-4,0950$ & $-3,2400$ & $-5,2000$ & 0,5497 \\
\hline
\end{tabular}

O uso das variáveis utilizadas na análise pode ser compreendido da seguinte forma:

- PREFIX: a composição da dívida pública com maior parcela de títulos prefixados é entendida como uma estratégia a ser tomada para a melhoria do gerenciamento da dívida pública no Brasil. A justificativa é que a parcela de títulos prefixados não está sujeita aos efeitos decorrentes das variações nos indexadores.

- P_SELIC: a parcela da dívida indexada à taxa Selic é relevante, pois é a mais sensível ao principal instrumento de política monetária utilizado pelo BCB.

- P_CAMBIO: a importância dessa variável é maior entre janeiro de 2000 e dezembro de 2002, especialmente devido à volatilidade da taxa de câmbio e à considerável parcela da dívida indexada a esta taxa.

- P_IP: o aumento da parcela da dívida indexada ao índice de preços sinaliza que a autoridade monetária está comprometida com a estabilidade de preços.

- credibilidade $(C R E D I B)$ : variável que afeta diretamente a dívida pública, pois é a variável que mede a confiabilidade dos agentes na condução da política monetária. A convergência da inflação para a meta permite a redução da taxa de juros, resultando em menor pressão sobre a dívida indexada à taxa de juros. $\mathrm{O}$ índice de credibilidade corresponde àquele desenvolvido por Mendonça (2003 e 2004a). Em específico, o índice de credibilidade possui valor igual a 1 quando a inflação anual esperada $(E(\pi))$ é igual à meta central e decresce de forma linear à medida que a expectativa inflacionária se desvia da meta anunciada. Destarte, o índice de credibilidade apresenta valor entre 0 e 1 se a inflação esperada estiver dentro dos limites máximo e mínimo $\left(\pi_{t}^{*}\right)$ estabelecidos para cada ano e assume valor zero quando a inflação esperada ultrapassa um desses limites. (MENDONÇA, 2004a, p. 347) 
- PMDFI: apresenta forte ligação com o comportamento da razão dívida/PIB. Segundo Giavazzi e Pagano (1990), por exemplo, um prazo de maturidade mais dilatado é um dos fatores capazes de reduzir a quantidade de títulos que precisam ser rolados durante um período de crise, ou seja, em condições desfavoráveis;

- taxa de juros básica (SELIC): esta variável se constitui no principal instrumento na busca da estabilidade de preços. Dado que durante o período de construção da credibilidade há uma tendência de se utilizar valores elevados para combater a inflação, isto implica a necessidade da geração de superávits primários para combater o crescimento da dívida pública;

- inflação $(I N F)$ : esta variável indica se o governo está ou não monetizando a dívida pública e, portanto, reduzindo a necessidade da geração de superávits primários. Por outro lado, uma política monetária contracionista em que se eleva a taxa de juros para conter a inflação provoca o aumento da dívida pública indexada aos juros, e

- necessidade de financiamento do setor público primário (NFSPP): a geração de superávits primários revela o comprometimento do governo com a solvência da dívida pública, o que, por sua vez, melhora a credibilidade na política econômica.

O modelo 1 considera a teoria sobre o gerenciamento da dívida pública desenvolvida por Calvo e Guidotti (1990). De acordo com essa visão, a indexação da dívida é capaz de reduzir o uso do imposto inflacionário. Logo, tal estratégia influencia a credibilidade da política econômica e, por conseguinte, a estabilidade da razão dívida/PIB. Além disso, conforme ressaltado por Giavazzi e Missale (2004), a estrutura de indexação da dívida pública é essencial para a estabilidade da economia. Destarte, o modelo tem como variável dependente a razão dívida/PIB e como variáveis independentes a parcela da dívida pública não indexada (títulos prefixados) e a parcela indexada (principais indexadores, isto é, taxa Selic, taxa de câmbio e índice de preços). Logo, a forma funcional é dada por:

$$
D I V P I B=f\left(p_{-} P R E F I X, p_{-} S E L I C, P_{-} C A M B I O, P_{-} I P\right)
$$

O modelo 2 leva em consideração o efeito da maturidade e a credibilidade na administração da dívida pública. De acordo com Calvo e Guidotti (1990), o alongamento do prazo da dívida é favorável à estabilidade da razão dívida/PIB. Para Giavazzi e Pagano (1990), essa estratégia diminui a necessidade de o governo recorrer ao mercado para rolar a dívida pública. De forma análoga, Missale, Giavazzi e Benigno (2004) concluíram que a adoção de uma estrutura de dívida mais longa é capaz de reduzir o risco de financiamento e, portanto, aumenta a probabilidade de sucesso do esforço fiscal. Assim, o modelo que captura o efeito do prazo médio da dívida pública e do nível de confiança do mercado no sucesso das medidas adotadas apresenta a seguinte estrutura:

$$
D I V P I B=f(P M D F I, C R E D I B)
$$


Com o objetivo de evitar a obtenção de resultados espúrios nas estimações realizadas, foram feitos os testes Dickey-Fuller Ampliado (ADF) e Phillips-Perron (PP) para detectar a presença de raiz unitária (vide Tabela A.1 - Apêndice) nas séries em consideração. De acordo com os testes realizados, verifica-se que as séries correspondentes à razão dívida/PIB, ao prazo médio da dívida, e à participação porcentual dos indexadores na dívida pública são integradas de primeira ordem, $I(1)$, para ambos os testes aplicados.

Pelo fato de as séries serem integradas de primeira ordem, é recomendável fazer a estimação utilizando a primeira diferença das variáveis. Todavia, isso pode implicar a perda da relação de longo prazo entre as variáveis. Em função disso é necessário testar a presença de co-integração entre as séries. Segundo Engle e Granger (1987), uma série temporal é dita co-integrada se há uma combinação linear de séries não-estacionárias que gere uma série estacionária. Em suma, se existirem relações de co-integração entre as variáveis, os resultados da regressão são válidos para o longo prazo. Em outras palavras, o caso de regressão espúria é eliminado.

A inclusão da constante e tendência foi definida com base no princípio de Pantula (HARRIS, 1995). Os resultados presentes no Apêndice (vide Tabelas A.2 e A.3) denotam que a especificação adequada para as séries DIVPIB, PREFIX, P_SELIC, P_CAMBIO e P_IP, referentes ao primeiro modelo (equação 1), deve ter constante e tendência no vetor de co-integração. Em relação às séries DIVPIB, PMDFI e CREDIB, referentes ao segundo modelo (equação 2), os resultados apresentados na Tabela A.4 (vide Apêndice) indicam que a especificação correta é aquela sem constante e sem tendência no vetor de co-integração. $\mathrm{O}$ teste de co-integração proposto por Johansen (1991), baseado na significância dos autovalores estimados (vide Tabela A.5 - Apêndice), indica que o traço estatístico rejeita a hipótese nula de não co-integração ao nível de $5 \%$ em ambos os modelos. Logo, fica evidenciado que há um equilíbrio de longo prazo entre as séries analisadas.

Com o objetivo de verificar se as medidas propostas pelos modelos de gerenciamento da dívida pública e acolhidas pelo governo brasileiro produziram os efeitos previstos, foram realizadas estimações pelo método dos Mínimos Quadrados Ordinários. É esperado que o aumento da participação de títulos prefixados e indexados ao índice de preços pressione menos a dívida pública, ao passo que a maior indexação à taxa Selic e à taxa de câmbio gerem maior pressão sobre a dívida. Tal como Missale, Giavazzi e Benigno (2002), espera-se que a importância relativa das variáveis $P R E F I X$ e $p_{-} I P$ seja maior que a das variáveis $p_{-} S E L I C$ e $p_{-} C A M B I O$ na explicação da razão dívida/PIB.

As regressões, em ambos os modelos, foram realizadas com defasagem de um período (um mês), tendo em vista a hipótese de exogeneidade estrita das variáveis independentes. Esta hipótese seria claramente violada sem as defasagens devido à influência contemporânea que a dívida pública (DIVPIB) tem em cada uma das variáveis em consideração. Destarte, a equação a ser estimada para o modelo 1 é dada por:

$$
D I V P I B=C+\beta_{1} P R E F I X(-1)+\beta_{2} p_{-} S E L I C(-1)+\beta_{3} p_{-} C A M B I O(-1)+\beta_{4} p_{-} I P(-1)
$$


Sendo os sinais esperados das relações expressos pelas derivadas parciais abaixo:

$$
\partial f / \partial P R E F I X>0, \partial f / \partial p_{-} S E L I C>0, \partial f / \partial P_{-} C A M B I O>0 \text { e } \partial f / \partial p_{-} I P>0
$$

Em particular, de acordo com o argumento apresentado por Giavazzi e Missale (2004), espera-se que mínimo $\left(\beta_{2}, \beta_{3}\right)>$ máximo $\left(\beta_{1}, \beta_{4}\right)$, pois a melhora no perfil da dívida pública brasileira estaria associada à diminuição da parcela indexada à taxa de câmbio e à taxa Selic e, por outro lado, ao aumento da parcela prefixada e da indexada ao índice de preços.

Ao se comparar os coeficientes das variáveis obtidos na regressão, verifica-se que os resultados estão de acordo com o esperado. ${ }^{7}$ Os resultados obtidos permitem constatar que as parcelas da dívida pública indexada à taxa Selic e à taxa de câmbio estão associadas à maior pressão de aumento sobre a dívida pública do que as parcelas prefixadas ou indexadas ao índice de preços (vide Tabela 2).

Tabela 2 - Estimações obtidas por MQO

\begin{tabular}{lccc}
\hline \multicolumn{4}{c}{$D I V P I B=C+\beta_{1} P R E F I X(-1)+\beta_{2} p_{-} S E L I C(-1)+\beta_{3} p_{-} C A M B I O(-1)+\beta_{4} p_{-} I P(-1)$} \\
\hline Variável & Coeficientes & Estatísticas-t & Probabilidades \\
\hline PREFIX $(-1)$ & 1,9197 & 4,7252 & 0,0000 \\
$P \_S E L I C(-1)$ & 2,0356 & 5,6227 & 0,0000 \\
$P \_C A M B I O(-1)$ & 2,0955 & 5,4658 & 0,0000 \\
$P \_I P(-1)$ & 1,8697 & 6,4943 & 0,0000 \\
$C$ & $-142,1129$ & $-4,0577$ & 0,0001 \\
\hline$R^{2}$ aj. $=0,7341$ & $\mathrm{~F}=54,8245$ & $\operatorname{Prob}(\mathrm{F})=0,0000$ & $\mathrm{n}^{\circ}$ obs. $=80$ \\
\hline
\end{tabular}

Seguindo o mesmo procedimento adotado para o caso anterior, a equação a ser estimada para o modelo 2 corresponde a:

$$
\operatorname{DIVPIB}=C+\beta_{1} \operatorname{PMDFI}(-1)+\beta_{2} \operatorname{CREDIB}(-1)
$$

cujos sinais esperados das relações correspondem a:

$$
\partial f / \partial P M D F i>0 \quad \text { e } \quad \partial f / \partial C R E D I B<0
$$

Ao contrário do que é preconizado pela maioria dos modelos sobre gerenciamento da dívida pública, espera-se que o alongamento do prazo médio da dívida provoque um aumento na razão dívida/PIB. A justificativa é que o alongamento da dívida implica um custo - o paga-

7 Para evitar o problema de heterocedasticidade, típico de séries macroeconômicas, os modelos foram reestimados corrigindo as estimativas pela matriz de Newey-West. 
mento de juros mais elevados. Dado que grande parte da dívida pública brasileira é indexada à taxa Selic, a conseqüência é uma possível elevação na razão dívida/PIB. Por outro lado, um aumento na credibilidade da condução da política monetária tende a provocar uma redução na taxa de juros e, por conseguinte, uma menor pressão no endividamento público.

Os resultados obtidos pela estimação do modelo (vide Tabela 3) revelam que, de fato, um aumento no prazo médio da dívida pública está associado a um aumento na razão dívida/ PIB. Em contrapartida, a credibilidade também possui significância estatística e o coeficiente é maior (em módulo) do que no caso para o prazo médio. Logo, a credibilidade representa um importante instrumento para combater o crescimento da dívida pública e, com isso, torna-se relevante para a prevenção dos riscos de default.

\section{Tabela 3 - Estimações em MQO}

\begin{tabular}{lccc}
\multicolumn{4}{c}{$D I V P I B=C+\beta_{1} P M D F I(-1)+\beta_{2} C R E D I B(-1)$} \\
\hline Variável & Coeficientes & Estatísticas-t & Probabilidades \\
\hline PMDFI(-1) & 0,36281 & 2,4642 & 0,0160 \\
$C R E D I B(-1)$ & $-3,30886$ & $-2,5194$ & 0,0139 \\
$C$ & 43,08956 & 9,4311 & 0,0000 \\
\hline$R^{2}$ aj. $=0,3851$ & $\mathrm{~F}=25,4257$ & $\operatorname{Prob}(\mathrm{F})=0,0000$ & no obs. $=80$ \\
\hline
\end{tabular}

Com o objetivo de analisar a conseqüência da estratégia adotada pelo governo brasileiro para a melhora do perfil da dívida pública combinada à adoção do regime de metas para inflação é feito um modelo VAR levando em conta as variáveis: NFSPP, DIVPIB, SELIC, INF, CREDIB, PMDFI, PREFIX e P_SELIC. Dado que o objetivo de um VAR é determinar o relacionamento entre as variáveis e não o de determinar os parâmetros estimados, foi aplicada a metodologia proposta por Sims (1980), na qual não é recomendada a diferenciação da variável mesmo se houver presença de raiz unitária.

Além da observação acima, é importante destacar que os modelos VAR têm sido considerados mais apropriados para a análise de relações interligadas e dos impactos dinâmicos provocados por choques. Ademais, devido à reconhecida dificuldade na interpretação dos coeficientes estimados para um VAR, a utilização da função impulso-resposta parcial é normalmente utilizada na análise.

Com o objetivo de eliminar o problema de ordenação de variáveis no VAR, a função de impulso generalizado é utilizada. O principal argumento para este procedimento é que o impulso resposta generalizado não varia se houver reordenação de variáveis no VAR. Conforme apontado por Lutkenpohl (1991), o método convencional para a análise da função impulso-resposta aplica a "hipótese da ortogonalidade", o que, por conseguinte, faz com que o resultado depen- 
da da ordenação das séries no VAR. Koop, Pesaran e Potter (1996), e Pesaran e Shin (1998) desenvolveram a função impulso-resposta generalizada como forma de eliminar o problema de ordenação das variáveis no VAR. Há duas vantagens potenciais na aplicação desse método (EWING, 2003): (i) a função de impulso-resposta generalizada fornece resultados mais robustos do que o método ortogonalizado, e (ii) devido ao fato de a ortogonalidade não ser imposta, a função impulso-resposta generalizada permite interpretar de forma mais acurada a resposta do impacto inicial decorrente de cada choque causado por uma variável sobre as demais.

Depois de estabelecida a ordem do VAR (vide Tabela A.6 - Apêndice), a análise da função-impulso resposta generalizada (vide Figura 6) foi realizada para um período de 36 meses. Observa-se que o efeito de um choque para o aumento na credibilidade está associado a uma elevação na necessidade de financiamento do setor público primário por aproximadamente 12 meses. Este resultado está de acordo com a perspectiva apresentada por King (1995) de que, para o desenvolvimento da credibilidade, há um custo para a sociedade por meio da elevação temporária no superávit primário. A conseqüência de um choque externo, transmitida pela variável prazo médio da dívida pública sobre o superávit primário, apresenta comportamento distinto para dois períodos. Para os primeiros 14 meses, percebe-se que há um aumento na necessidade de financiamento do setor público primário. Isto significa que o aumento no prazo médio possui um custo no curto prazo. Entretanto, depois de ultrapassado esse período, a estratégia contribui para a redução do superávit primário. Quanto aos resultados relativos aos títulos prefixados e àqueles indexados à Selic, os gráficos revelam que as regularidades apresentam um declínio dos impactos, tendendo a serem anuladas ao longo do tempo.

O impacto provocado por um choque transmitido pela variável credibilidade sobre a dívida pública revela que há um efeito benéfico no curto prazo (aproximadamente 20 meses). Conforme esperado, um aumento na credibilidade tende a reduzir a razão dívida/PIB. De forma diferente do que era previsto pela maioria dos modelos de gerenciamento da dívida, um aumento no prazo médio não está associado a uma redução na razão dívida/PIB (o impacto é neutralizado depois de transcorridos 34 meses). Este resultado é consistente com a estimação realizada em MQO para a equação 2. Ou seja, um aumento no prazo médio da dívida pública está associado, por exemplo, à necessidade de pagamento de um prêmio de risco mais elevado, fazendo com que haja uma pressão para o aumento detectado. Em relação aos choques transmitidos pelos títulos prefixados e indexados à Selic, observa-se que os efeitos sobre a dívida pública ficam confinados a um período inferior a dez meses, não sendo, portanto, cruciais para a análise do caso brasileiro. 


\section{Figura 6 - Funções de impulso-resposta para o VAR}
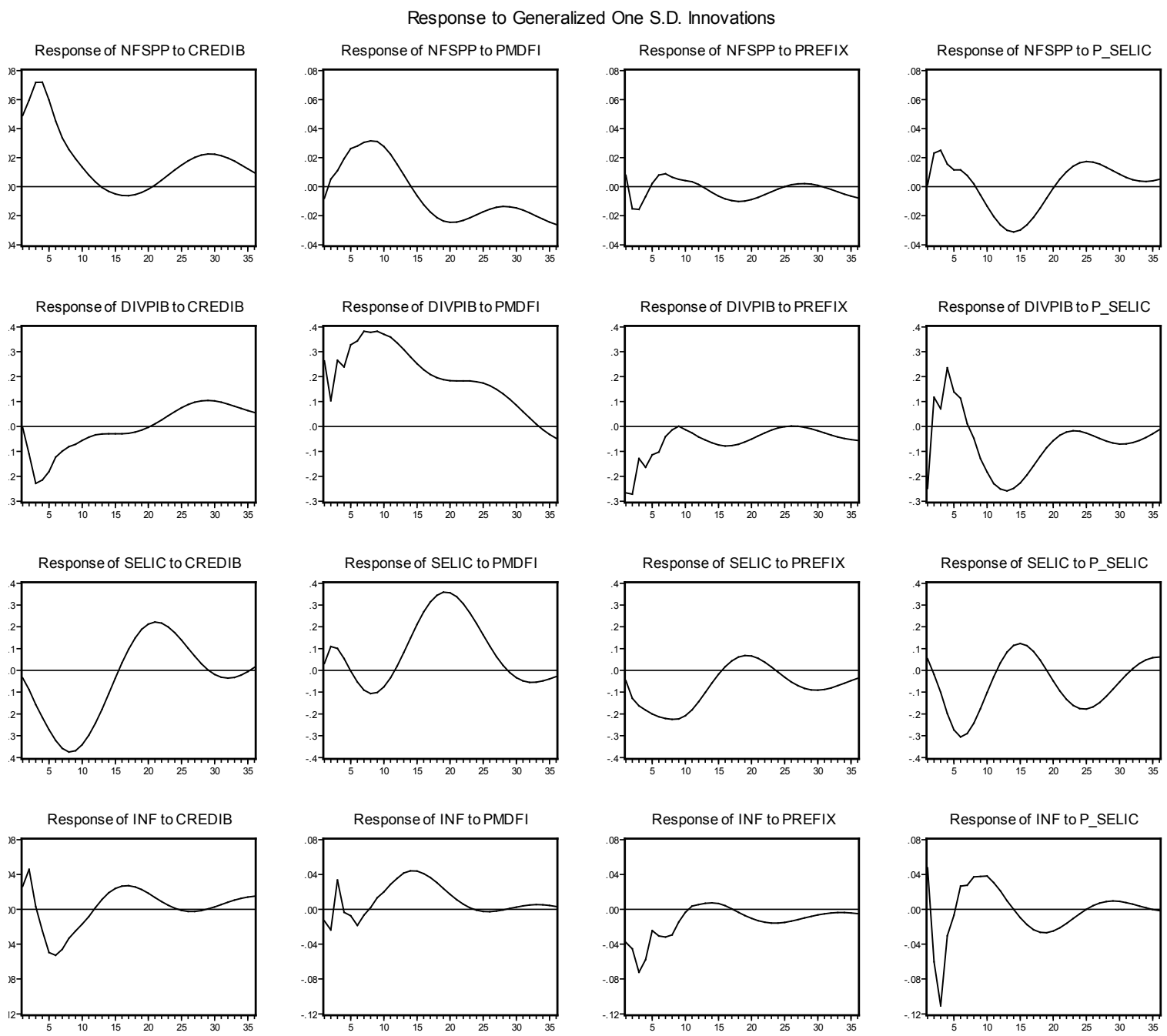

Quanto ao efeito da credibilidade sobre a taxa Selic, observa-se que um aumento na credibilidade tende a provocar uma redução na taxa de juros por aproximadamente 15 meses. A justificativa é que, com uma credibilidade mais elevada, menor é o esforço do Banco Central para a convergência entre as expectativas de inflação e a meta. A justificativa para o efeito temporário se deve ao fato de a credibilidade na condução da política monetária não estar consolidada no período sob análise. Em relação aos efeitos das estratégias de gerenciamento da dívida pública sobre a taxa Selic, verifica-se que tanto a indexação dos títulos da dívida pública pela Selic quanto a utilização de títulos prefixados contribuem para uma queda temporária na taxa de juros. Esta observação se deve ao fato de que, com o uso dessas estratégias, o risco de default é reduzido, o que, por conseguinte, implica um menor pagamento para o prêmio de risco. Tal como nos casos anteriores, o efeito de um choque transmitido pelo prazo médio da 
dívida pública não é vantajoso. Neste caso, a pressão para o aumento na taxa de juros (depois de transcorrido 12 meses) se deve à exigência que os investidores fazem para trocarem seus títulos por outros com prazo de vencimento alongado.

No que se refere ao impacto sobre a inflação, verifica-se que, com uma defasagem de quatro meses, a credibilidade contribui para uma redução nessa variável por um período de cerca de nove meses. Ou seja, o efeito de curto prazo causado por um aumento na credibilidade contribui tanto para o equilíbrio fiscal quanto para o controle da inflação. O efeito temporário na redução da inflação também é capturado pelos choques transmitidos pelos títulos indexados à Selic e pelos títulos prefixados. No caso dos títulos indexados à Selic, é natural que, para tornar esses títulos mais atrativos, ocorra uma elevação na taxa Selic, o que, por sua vez, contribui para uma redução na taxa de inflação. Efeito similar é observado para o aumento na participação de títulos prefixados na composição da dívida pública. Nesse caso, com uma estrutura da dívida mais prognosticada, o risco de um desequilíbrio fiscal é reduzido e, portanto, há a criação de um ambiente macroeconômico propício à redução da inflação. Ao contrário do efeito provocado, por exemplo, por um incremento na credibilidade, observa-se que a estratégia de alongar o prazo médio da dívida não se revela adequada sob uma perspectiva de curto prazo, nem para o equilíbrio fiscal nem para o controle da inflação.

\section{CONCLUSÃo}

A utilização da taxa de juros como principal instrumento para a obtenção da meta de inflação e o fato de grande parte da dívida pública estar indexada a essa taxa faz com que haja uma reciprocidade entre a condução da política monetária e o gerenciamento da dívida pública. Foi observado que o uso de uma política monetária voltada para um processo de desinflação provocou um efeito que não pode ser negligenciado sobre o equilíbrio fiscal. Ademais, a mudança anunciada pelo governo brasileiro para uma melhora do perfil da dívida pública contribuiu para uma rigidez para baixo da taxa Selic.

As evidências empíricas revelaram que a estratégia de alongar o prazo médio da dívida pública não tem se mostrado eficiente para o caso brasileiro. A justificativa é que essa estratégia implica um aumento na taxa de juros que se traduz em um incremento na razão dívida/PIB. Por outro lado, o aumento na participação de títulos prefixados e indexados ao índice de preços mostra-se mais adequado para o gerenciamento da dívida pública brasileira. Uma variável que merece destaque na análise é a credibilidade. Foi observado que um aumento na credibilidade é capaz de contribuir tanto para uma redução na dívida pública quanto para o controle da inflação. Todavia, o desenvolvimento da credibilidade está associado a um custo temporário (aumento do superávit primário).

Portanto, para que uma política econômica baseada no equilíbrio fiscal e no alcance das metas para inflação tenha êxito é preciso combinar um gerenciamento adequado da dívida pú- 
blica (por exemplo, via aumento na participação de títulos prefixados e indexados ao índice de preços) com a definição de uma taxa de juros que faça com que as expectativas convirjam para a meta anunciada. Em suma, uma estrutura da dívida pública menos indexada à taxa Selic dá maior liberdade para que a política monetária possa se concentrar na busca da estabilidade de preços. Logo, devido à maior facilidade de a autoridade monetária obter as metas de inflação, há um aumento na credibilidade, o que, por conseguinte, contribui tanto para o alcance de uma inflação baixa e estável quanto para uma menor razão dívida/PIB.

\section{REFERÊNCIAS}

BARRO, R. J. Optimal management of indexed and nominal debt. Annals of Economics and Finance, n. 4, p. 1-15, 2003.

.; GORDON, D. Rules, discretion and reputation in a model of monetary policy. Journal of Monetary Economics, 12, North-Holland, p. 101-121, 1983.

CALVO, G. A.; GUIDOTTI, P. E. Indexation and maturity of government bonds: an exploratory model. In: DORNBUSCH, R.; DRAGHI, M. (Eds.). Public debt management: theory and history. Cambridge: Cambridge University Press, 1990.

ENGLE, R. F.; GRANGER, C. W. J. Cointegration and error correction: representation, estimations and testing. Econometrica, v. 55, n. 2, p. 251-76, 1987.

EWING, B.T. The response of the default risk premium to macroeconomic shocks. The Quarterly Review of Economics and Finance, v. 43, p. 261-272, 2003.

FAVERO, C.; GIAVAZZI, F. Targeting inflation when debt and risk premia are high: lessons from Brazil. IGIER, Bocconi: MIT, May 2003. Mimeo.

GIAVAZZI, F.; MISSALE, A. Public debt management in Brazil. NBER Working Papern. 10394, March 2004.

GIAVAZZI, F.; PAGANO, M. Confidence crises and public debt management. In: DORNBUSCH, R.; DRAGHI, M. (Eds.). Public debt management: theory and history. Cambridge: Cambridge University Press, 1990.

HARRIS, R. Using cointegration analysis in econometric modelling. London: Prentice Hall, Harvester Wheatsheaf, 1995.

JOHANSEN, S. Estimation and hypothesis testing of cointegration vectors in gaussian vector autoregressive models. Econometrica, v. 59, n. 6, p. 1551-1580, 1991.

KING, M. Commentary: monetary policy implications of greater fiscal discipline. Budget deficits and debt: issues and options. Federal Reserve Bank of Kansas City, Aug.-Sept. 1995. p. 171-183.

KOOP, G.; PESARAN, M. H.; POTTER, S. M. Impulse response analysis in non-linear multivariate models. Journal of Econometrics, v. 74, n. 1, p. 119-147, 1996.

LUTKENPOHL, H. Introduction to multiple time series analysis. Berlin: Springer, 1991.

MACKINNON, J. G.; HAUG, A. A.; MICHELIS, L. Numerical distribution functions of likelihood ratio tests for cointegration. Journal Applied Econometrics, v. 14, . 5, p. 563-577, 1999.

MENDONÇA, H. F. de. A teoria da credibilidade da política monetária: desdobramentos do debate regras versus discrição. Revista de Economia Política, v. 22, n. 3, p. 46-64, jul.-set. 2002. 
. Credibilidade das metas de inflação: uma análise aplicada ao caso brasileiro. Revista Economia Aplicada, São Paulo, v. 7, n. 4, p. 729-742, 2003.

Mensurando a credibilidade do regime de metas inflacionárias no Brasil: uma análise a partir de dois índices. Revista de Economia Política, São Paulo, v. 24, n. 3, p. 344-350, 2004 a.

. A importância do tamanho, do prazo médio, e da estrutura de vencimento para a administração da dívida pública: uma análise a partir dos modelos de Giavazzi-Pagano (1990) e de Calvo-Guidotti (1990). Economia e Sociedade, v. 13, n. 1, p. 1-19, 2004 b.

. Towards credibility from inflation targeting: the Brazilian experience. Applied Economics, v. 39, p. 2599-2615, 2007.

.; VIVIAN, V. S. Public-debt management: the Brazilian experience. CEPAL Review, n. 94, p. 149-162, 2008.

MISSALE, A. F.; GIAVAZZI, F.; BENIGNO, P. How is debt managed? Learning from fiscal stabilization. Scandinavian Journal of Economics, v. 104, n. 3, p. 443-469, 2002.

PESARAN, M. H.; SHIN, Y. Generalized impulse response analysis in linear multivariate models. Economic Letters, v. 58, n. 1, p. 17-29, 1998.

SARGENT, T. J.; WALLACE, N. Some unpleasant monetarist arithmetic. Quarterly Review, Federal Reserve Bank of Minneapolis, p. 1-17, Fall 1981.

SIMS, C. Macroeconomics and reality. Econometrica, v. 48, n. 1, p. 1-48, 1980. 


\section{APÊNDICE}

Tabela A.1 - Teste de raiz unitária (ADF e PP)

\begin{tabular}{lcccc|cccc}
\hline & & \multicolumn{3}{c}{ ADF } & & & \multicolumn{3}{c}{$P P$} & \\
\hline Séries & Def & teste & valor crítico & Valor crítico & Def & teste & $\begin{array}{c}\text { valor crítico } \\
\text { Valor crítico }\end{array}$ \\
\hline DIVIPIB & 1 & 0,015921 & $-2,595340$ & $-1,945081$ & 1 & $-0,026639$ & $-2,594946$ & $-1,945024$ \\
D(DIVIPIB) & 0 & $-11,72037$ & $-2,595340$ & $-1,945081$ & 2 & $-11,54682$ & $-2,595340$ & $-1,945081$ \\
SELIC & 1 & $-3,60608$ & $-3,516676$ & $-2,898623$ & 6 & $-0,636802$ & $-2,594563$ & $-1,944969$ \\
D(SELIC) & & & & & 3 & $-3,019157$ & $-2,594946$ & $-1,945024$ \\
INF & 0 & $-3,981473$ & $-3,515536$ & $-2,899619$ & 5 & $-3,843735$ & $-2,595340$ & $-1,945081$ \\
CREDIB & 1 & $-1,649286$ & $-2,595340$ & $-1,945081$ & 0 & $-1,134392$ & $-2,594946$ & $-1,945024$ \\
D(CREDIB) & 0 & $-6,611015$ & $-2,595340$ & $-1,945081$ & 6 & $-6,468853$ & $-2,595340$ & $-1,945081$ \\
CAMBIO & 1 & $-0,043667$ & $-2,595340$ & $-1,945081$ & 4 & $-0,065885$ & $-2,594946$ & $-1,945024$ \\
D(CAMBIO) & 0 & $-6,496534$ & $-3,517847$ & $-2,899619$ & 2 & $-6,558536$ & $-2,595340$ & $-1,945081$ \\
NFSPP & 0 & 0,431496 & $-2,594946$ & $-1,945024$ & 2 & 0,433048 & $-2,594946$ & $-1,945024$ \\
D(NFSPP) & 0 & $-8,574757$ & $-2,595340$ & $-1,945081$ & 2 & $-8,572332$ & $-2,595340$ & $-1,945081$ \\
PMDFI & 1 & 0,269323 & $-2,594946$ & $-1,945024$ & 3 & 0,351147 & $-2,594563$ & $-1,944969$ \\
D(PMDFI) & 0 & $-6,474254$ & $-2,594946$ & $-1,945024$ & 2 & $-6,432412$ & $-2,594946$ & $-1,945024$ \\
PREFIX & 9 & 1,444514 & $-2,598416$ & $-1,945525$ & 7 & 3,683827 & $-2,594563$ & $-1,944969$ \\
D(PREFIX) & 8 & $-1,005760$ & $-2,598416$ & $-1,945525$ & 7 & $-9,514414$ & $-3,516676$ & $-2,899115$ \\
P_SELIC & 0 & $-1,104077$ & $-2,594563$ & $-1,944969$ & 5 & $-0,895560$ & $-2,594563$ & $-1,944969$ \\
D(P_SELIC) & 2 & 3,381389 & $-2,595745$ & $-1,945139$ & 4 & $-7,353868$ & $-2,594946$ & $-1,945024$ \\
P_CAMBIO & 0 & $-1,563170$ & $-2,594563$ & $-1,944969$ & 5 & $-1,343831$ & $-2,594563$ & $-1,944969$ \\
D(P_CAMBIO) & 0 & $-7,790070$ & $-2,594946$ & $-1,945024$ & 5 & $-8,103853$ & $-2,594946$ & $-1,945024$ \\
P_IP & 1 & 1,540391 & $-2,594946$ & $-1,945024$ & 4 & 2,166139 & $-2,594563$ & $-1,944969$ \\
D(P_IP) & 0 & $-4,944167$ & $-2,594946$ & $-1,945024$ & 4 & $-5,035256$ & $-2,594946$ & $-1,945024$ \\
\hline & & & & & & & & \\
\hline
\end{tabular}

Nota: Teste ampliado de Dickey-Fuller (ADF) - o número de defasagens utilizado para cada série foi definido de acordo com o critério de Schwarz (SC). Não foi usada constante ou tendência para as séries DIVPIB, D(DIVPIB), CREDIB, D(CREDIB), CAMBIO, D(CAMBIO), PMDFi, D(PMDFi), PREFIX, p_SELIC, d(P_SELIC), p_CAMBIO, D(p_ CAMBIO), p_IP, D(p_IP). Foi usado constante para as séries: SELIC e INF. No teste Phillips-Perron a defasagem usada é a aplicada para Bartlett kernel. Não foi usada constante e tendência para as séries DIVPIB, D(DIVPIB), SELIC, D(SELIC), INF, CREDIB, D(CREDIB), CAMBIO, D(CAMBIO), NFSPP, D(NFSPP) e D(PREFIX). 
Tabela A.2 - Critério de SC e HQ para ordem do VAR

\begin{tabular}{ccc|cc}
\hline \multirow{2}{*}{ Defasagens } & \multicolumn{2}{c|}{ Modelo 1 } & \multicolumn{2}{c}{ Modelo 2 } \\
\cline { 2 - 5 } & $\mathrm{SC}$ & $\mathrm{HQ}$ & $\mathrm{SC}$ & $\mathrm{HQ}$ \\
\hline 0 & 23,72274 & 23,63068 & 10,03482 & 9,979586 \\
1 & $10,99263^{*}$ & $10,44029^{\star}$ & $4,210806^{*}$ & $3,989870^{*}$ \\
2 & 11,84617 & 10,83355 & 4,376815 & 3,990177 \\
3 & 12,60741 & 11,13450 & 4,807804 & 4,255465 \\
4 & 12,90516 & 10,97197 & 5,196529 & 4,478488 \\
\hline
\end{tabular}

Nota: * denota a ordem selecionada pelo critério. SC: critério de Schwarz. HQ: critério de Hannan-Quinn.

Tabela A.3 - Número de relações de co-integração - modelo 1

\begin{tabular}{|c|c|c|c|c|c|c|}
\hline \multicolumn{2}{|c|}{ Tendência: } & Não & Não & Linear & Linear & Quadrática \\
\hline \multirow{2}{*}{\multicolumn{2}{|c|}{ Tipo de teste }} & Sem const. & Constante & Constante & Constante & Constante \\
\hline & & sem tend. & sem tend. & sem tend. & Iendencia & Iendencla \\
\hline \multicolumn{2}{|l|}{ Traço } & 3 & 3 & 1 & 1 & 1 \\
\hline \multicolumn{2}{|l|}{ Max-Eig } & 3 & 1 & 0 & 0 & 0 \\
\hline \multirow{6}{*}{ 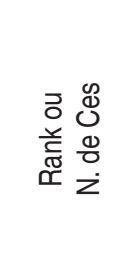 } & 0 & 10,60070 & 10,60070 & 10,41436 & 10,41436 & 10,39921 \\
\hline & 1 & 10,38815 & 10,40537 & 10,26108 & 10,26302 & 10,22628 \\
\hline & 2 & 10,28979 & 10,33033 & 10,24380 & $10,18570^{*}$ & 10,19610 \\
\hline & 3 & 10,31514 & 10,37765 & 10,33323 & 10,25438 & 10,24742 \\
\hline & 4 & 10,46648 & 10,49843 & 10,43077 & 10,37032 & 10,38052 \\
\hline & 5 & 10,70005 & 10,67830 & 10,67830 & 10,60693 & 10,60693 \\
\hline
\end{tabular}

Nota: Critério de informação de Akaike por Rank (linhas) e Modelo (colunas). Selecionado (0,05 nível) - valores críticos MacKinnon-Haug-Michelis (1999).

Tabela A.4 - Número de relações de co-integração - modelo 2

\begin{tabular}{|c|c|c|c|c|c|c|}
\hline \multicolumn{2}{|c|}{ Tendência: } & Não & Não & Linear & Linear & Quadrática \\
\hline \multirow{2}{*}{\multicolumn{2}{|c|}{ Tipo de teste }} & Sem const. & Constante & Constante & Constante & Constante \\
\hline & & Sem tend. & Sem tend. & Sem tend. & Tendência & Tendência \\
\hline \multicolumn{2}{|l|}{ Traço } & 1 & 1 & 1 & 0 & 1 \\
\hline \multicolumn{2}{|l|}{ Max-Eig } & 1 & 0 & 0 & 0 & 0 \\
\hline \multirow{4}{*}{ 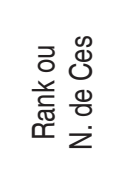 } & 0 & 3,887573 & 3,887573 & 3,958403 & 3,958403 & 3,979266 \\
\hline & 1 & $3,793521^{*}$ & 3,796857 & 3,844576 & 3,869684 & 3,904831 \\
\hline & 2 & 3,847144 & 3,864093 & 3,886831 & 3,917815 & 3,940725 \\
\hline & 3 & 3,998206 & 3,963042 & 3,963042 & 3,986922 & 3,986922 \\
\hline
\end{tabular}

Nota: Critério de informação de Akaike por Rank (linhas) e Modelo (colunas). Selecionado (0,05 nível) - valores críticos MacKinnon-Haug-Michelis (1999). 
Tabela A.5 - Teste de co-integração de Johansen (DIVPIB, PREFIX, P_SELIC, P_CAMBIO e P_IP )

\begin{tabular}{ccccc}
\hline $\mathrm{H}_{0}$ & Autovalor & Traço estatístico & Valor crítico $(0,05)^{\text {Prob. }^{* *}}$ \\
\hline $\mathrm{R}=0^{*}$ & 0,349370 & 94,78682 & 88,80380 & 0,0173 \\
$\mathrm{R} \leq 1$ & 0,299389 & 60,83152 & 63,87610 & 0,0878 \\
$\mathrm{R} \leq 2$ & 0,189256 & 32,72309 & 42,91525 & 0,3504 \\
$\mathrm{R} \leq 3$ & 0,150017 & 16,14863 & 25,87211 & 0,4807 \\
$\mathrm{R} \leq 4$ & 0,041010 & 3,308068 & 12,51798 & 0,8381 \\
\hline & (DIVPIB, PMDFI e CREDIB $)$ & \\
\hline $\mathrm{R}=0^{*}$ & 0,218039 & 27,26003 & 24,27596 & 0,0204 \\
$\mathrm{R} \leq 1$ & 0,093601 & 7,829901 & 12,32090 & 0,2502 \\
$\mathrm{R} \leq 2$ & 0,000837 & 0,066145 & 4,129906 & 0,8330 \\
\hline
\end{tabular}

Nota: (*) indica rejeição de $\mathrm{H}_{0}$ no nível de significância de 5\%. (**) MacKinnon-Haug-Michelis (1999) p-valor.

Tabela A.6 - Critério de SC e HQ para ordem do VAR

\begin{tabular}{lll}
\hline & $\mathrm{SC}$ & $\mathrm{HQ}$ \\
\hline 0 & 30,28644 & 30,08391 \\
1 & $11,97956^{\star}$ & $9,549265^{\star}$ \\
2 & 14,87359 & 10,21552 \\
3 & 17,16666 & 10,28083 \\
4 & 18,79690 & 9,683300 \\
\hline
\end{tabular}

Nota: * denota a ordem selecionada pelo critério. SC: critério de Schwarz. HQ: critério de Hannan-Quinn. 
